\title{
Abrindo os olhos da sociedade para que os renais crônicos possam dormir melhor
}

\author{
Márcio Moysés de Oliveira \\ Professor Adjunto do Departamento de Morfologia da Universidade Federal do Maranhão - UFMA, São Luis-MA, Brasil.
}

A insuficiência renal crônica é uma doença de elevada morbidade e mortalidade ${ }^{1}$ e já atinge aproximadamente $11 \%$ da população mundial segundo dados da Sociedade Brasileira de Nefrologia. Os indivíduos que têm maior propensão ao seu desenvolvimento são as que apresentam pressão alta, diabetes, doenças cardiovasculares, casos de doenças renais crônicas na família e idosos.

No levantamento de 2010, no Brasil, a população de risco para doença renal crônica aproximava-se dos 60 milhôes de habitantes, sendo que mais de 13 milhões já eram portadores da doença e cerca de 90 mil encontravase em tratamento de diálise no País.

Devido a este número crescente de casos e o impacto que isso leva para o sistema de saúde e para a sociedade ${ }^{1,2}$, o diagnóstico precoce tem sido um grande desafio e uma meta a se alcançar, o que tem incentivado o governo e as sociedades de saúde a promoverem campanhas de prevenção e rastreamento com preconização de exames laboratoriais.

Os transtornos do sono estão fortemente associados com os pacientes em diálise, em pacientes que requerem cuidados crônicos de saúde e que tenham a qualidade de vida comprometida. As queixas relacionadas ao sono em pacientes com insuficiência renal crônica terminal (em diálise ou não) são freqüentes e de alta prevalência, envolvendo transtornos do sono como: apneia do sono, movimentos periódicos dos membros, insônia e síndrome das pernas inquietas. Identificar e tratar pacientes com doença renal crônica que dormem mal pode melhorar significativamente a sua sobrevida e a qualidade de vida $^{1,3-5}$.

No artigo "Avaliação da qualidade e quantidade do sono em pacientes renais crônicos submetidos à hemodiálise" 6 os autores tiveram como objetivo avaliar a quantidade e qualidade do sono dos pacientes portadores de doença renal crônica terminal em diálise, utilizando instrumentos de simples aplicação como o Diário do Sono e o Índice de qualidade de sono de Pittsburgh, que apesar da pouca adesão dos pacientes, descreveram dados similares a descrita na literatura mundial, onde $75 \%$ relatam sono comprometido e $14 \%$ com qualidade de sono ruim no primeiro ano de diálise e de 45 a $80 \%$ de prevalência entre os pacientes com insuficiência renal crônica de modo geral ${ }^{3,4}$.

Merece destaque a utilização do diário do sono como uma avaliação subjetiva simples da quantidade do sono e como preditor de possíveis causas de modificaçóes da quantidade do sono, por exemplo: 1) alteraçóes da latência do sono como a insônia, ansiedade e depressão; 2) transtornos relacionados à fragmentação do sono como a apnéia, despertares e quadros álgicos; 3) transtornos dos movimentos relacionados ao sono como a síndrome das pernas inquietas e movimentos periódicos dos membros, todos muito comuns em portadores de doença renal crônica terminal ${ }^{1,7}$, geralmente a maioria destas condiçóes clínicas é avaliada e comprovada por instrumentos complexos e objetivos (polissonografia, actigrafia, etc). Infelizmente os dados ficaram comprometidos pelo número muito pequeno de participantes neste estudo que preencheram o diário do sono, porém fica o método como opção para futuras pesquisas.

O levantamento e divulgação de dados associados à qualidade e quantidade do sono dos pacientes em diálise é essencial para otimização das intervenções e desfechos clínicos para esta população específica, com isto levamos mais dignidade, esperança e qualidade de vida aos pacientes e à sociedade que os envolve. 


\section{REFERÊNCIAS}

1.de Oliveira MM, Conti CF, Valbuza JS, de Carvalho LB, do Prado GF. The pharmacological treatment for uremic restless legs syndrome: evidence-based review. Mov Disord 2010;25:1335-42.

http://dx.doi.org/10.1002/mds.22955

2.Sesso R, Rodrigues Neto JF, Ferraz MB. Impact of socioeconomic status on quality of life of ESRD patients. Am J Kidney Dis 2003;41:186-95.

http://dx.doi.org/10.1053/ajkd.2003.50003

3.Unruh ML, Buysse DJ, Dew MA, Evans IV, Wu AW, Fink NE, et al. Sleep Quality and Its Correlates in the First Year of Dialysis. Clin J Am Soc Nephrol 2006;1:802-10.

http://dx.doi.org/10.2215/CJN.00710206

4.Iliescu EA, Yeates KE, Holland DC. Quality of sleep in patients with chronic kidney disease. Nephrol Dial Transplant 2004;19:95-9.

http://dx.doi.org/10.1093/ndt/gfg 423

5.Sesso R, Yoshihiro MM. Time of diagnosis of chronic renal failure and assessment of quality of life in hemodialysis patients. Nephrol Dial Transplant 1997;10:2111-6.

http://dx.doi.org/10.1093/ndt/12.10.2111

6.Guimarães CKD, Alves DAG, Guimarães LHCT. Avaliação da qualidade e quantidade do sono em pacientes renais crônicos submetidos à hemodiálise. Rev Neurocienc 2011;19:609-13.

7.Parker KP, Kutner NG, Bliwise DL, Bailey JL, Rye DB. Nocturnal sleep, daytime sleepiness, and quality of life in stable patients on hemodialysis. Health Qual Life Outcomes 2003;1:68.

http://dx.doi.org/10.1186/1477-7525-1-68 